\title{
Geochemical Assessment for Gold in Sediments of Gora River in Minna Area, North-central Nigeria
}

\author{
S.O. Obaje ${ }^{1, *}$, F.C. Ugbe ${ }^{2}$, I.A. Akpoborie ${ }^{2}$, A.O. Edebiri ${ }^{2}$ \\ ${ }^{1}$ Department of Earth Sciences, Salem University, Nigeria \\ ${ }^{2}$ Department of Geology, Delta State University, Nigeria
}

Copyright (C) 2015 Horizon Research Publishing All rights reserved.

\begin{abstract}
Investigation was carried out on sediments of River Gora to geochemically assess for gold and its origin. The study area is situated in Minna in the North-Central geo-political zone of Nigeria. The area is constrained within latitude $9^{0} 33^{\prime} \mathrm{N}$ and $9^{0} 35^{\prime} \mathrm{N}$ and longitude $6^{0} 34^{\prime} \mathrm{E}$ and $6^{0}$ 35 'E. Major and trace elements were analyzed using X-Ray Fluorescence spectrometry method. To decipher the factors responsible for the elemental association with gold, factor analysis, principal component analysis and cluster analysis were performed. The result revealed two main clusters of variables classified into three groups, namely: cluster 1, cluster 2(a) and cluster 2(b). Cluster 1 is made up of $\mathrm{Ba}$ and $\mathrm{Sr}$, while cluster 2(a) consists of $\mathrm{Rb}, \mathrm{Cu}, \mathrm{Zn}, \mathrm{Cr}, \mathrm{Ba}$ and cluster 2(b) contains As, Mn, Mo, Fe, Au, Sb, Ni, Pb. The principal component analysis solution revealed four components, namely: component 1 ( $\mathrm{Sb}, \mathrm{Ba}, \mathrm{As}, \mathrm{Zn}, \mathrm{Cu}, \mathrm{Ni}$, $\mathrm{Cr}, \mathrm{Fe}$ ), component 2 ( $\mathrm{Ba}, \mathrm{As}, \mathrm{Pb}, \mathrm{Zn}, \mathrm{Cu}, \mathrm{Cr}, \mathrm{Fe}$ ), component 3 (Sb, As, Zn, Sr, Ni, Cr, Fe) and component 4 ( $\mathrm{Au}, \mathrm{Sb}, \mathrm{Ba}, \mathrm{As}, \mathrm{Pb}, \mathrm{Cu}, \mathrm{Mo}, \mathrm{Cr}$ ). The elemental associations suggested sulphide-gold mineralization within the surrounding schist and granitoids as possible source rocks.
\end{abstract}

Keywords Geochemical exploration, placer gold, Gora river, Minna, Nigeria

\section{Introduction}

The study area is situated in Minna in the North-Central geo-political zone of Nigeria. The area is constrained within latitude $9033^{\prime} \mathrm{N}$ and $9035^{\prime} \mathrm{N}$ and longitude $6034^{\prime} \mathrm{E}$ and 60 $35^{\prime} \mathrm{E}$ (Fig. 1). Accessibility to the sampling locations is via Chanchaga-Tegina road, minor roads, footpaths and the river channel. The study area is covered by "Guinea woodland savannah" vegetation. This vegetation comprises typical combinations of tall grasses, shrub and scattered trees with denser tree cover along drainage channels. Cotton and sugar plantations are found in the study area. The vegetation cover helps to prevent wind-scoring of unconsolidated soils during the wet season, but not during the dry season [1].

The main aim of the study was to investigate sediments from River Gora for placer gold and its origin. To achieve the goal, objectives involving fieldwork, laboratory analysis, data interpretation and statistical methods were used to reduce the data to useful forms for meaningful interpretation and drawing of inferences.

Twenty-four samples were collected from various locations in Gora river bed with the main aim of carrying out geochemical exploration for gold and assessment of the origin of gold mineralization in the study area. To achieve the project aim, objectives involving field and laboratory techniques were engaged. The samples were wet sieved in the field and placed in kraft envelops to dry gradually at the base camp and later transported to the laboratory for further treatment. Each sample was oven dried, sieved and $10 \mathrm{~g}$ of $63 \mu \mathrm{m}$ fractions were taken for further treatment and analyzed for major and trace elements using X-Ray Fluorescence spectrometry method.

The dominant lithologic unit in River Gora area is schist. The area has undulating topography comprising high hills and valleys with covered vegetation. The highest elevation within the area is about 240 meters above mean sea level. The area is drained principally by River Gora. The drainage pattern of the area is dendritic. Most of the streams that drain the area are seasonal. Several quartz veins cross-cut the schist rocks in the area. 


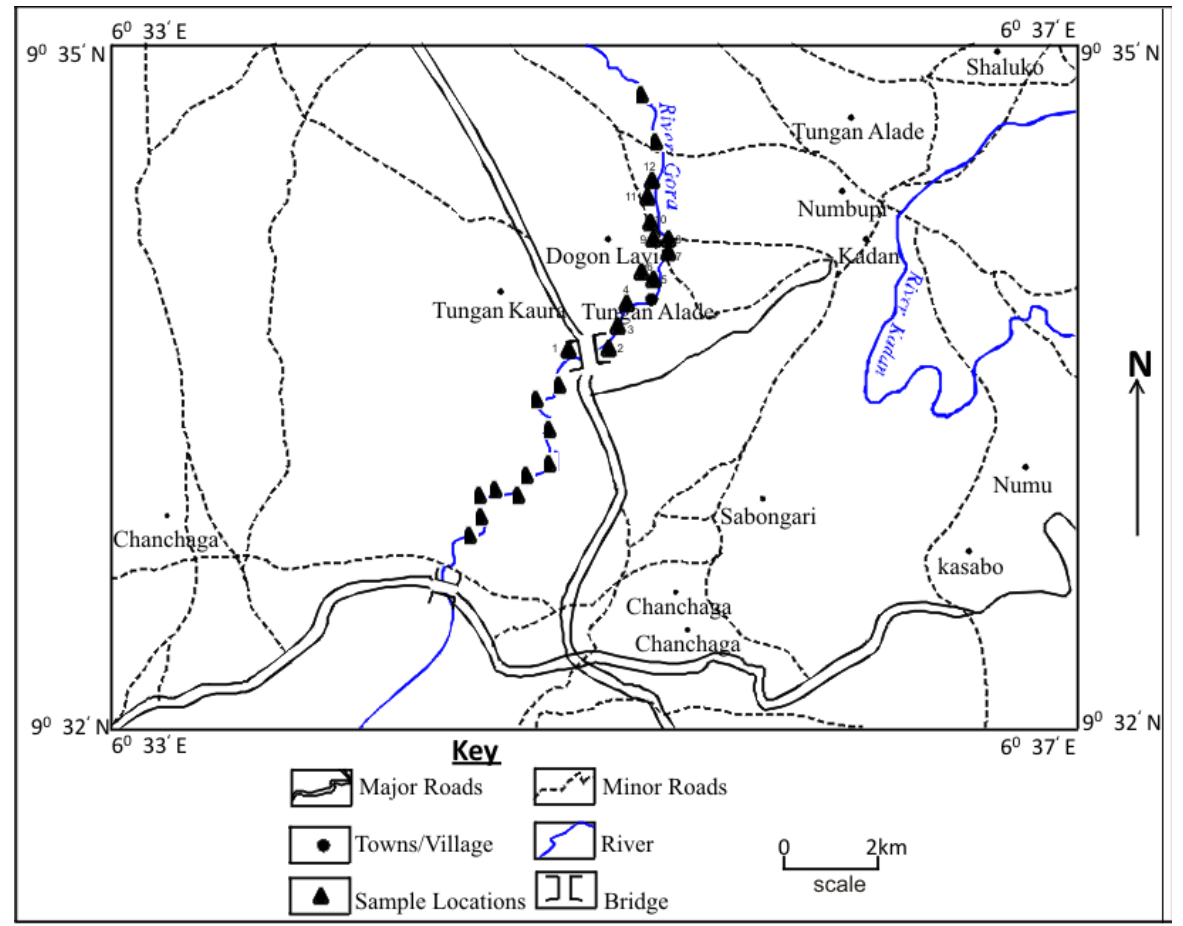

Figure 1. Road Map of Study Area showing Sampling

\section{Materials and Methods}

In the field, the following materials were used, namely: location map, plastic samplers, plastic panning bowls, set of sieves, global positioning system (GPS), digital camera, kraft envelops, nylon bags, plastic hand gloves, field notebook and rubber boots. In the laboratory, the materials used are weighing balance (model: ScoutPro SPU601 $\mathrm{S} / \mathrm{N}-7123270179$ ), brush, set of sieves, sieves shaker (STSJ-4 digital high frequency sieves shaker, S/N-100064) and cardboard.

The fieldwork involved the collection of Gora river sediments and the recording of the geographical coordinates and elevations of the sediments sampling points using GPS. Twenty-four stream sediments taken at depths of $30-50 \mathrm{~cm}$ with the aid of plastic sampler were wet sieved and packed into labeled brown kraft envelopes, left to sun dry and transported to field base camp for onward transmission to the laboratory. Panning was also done to confirm the presence of gold in the selected sampling location.

Sample preparation via dry sieving was carried out in the Department of Geology Laboratory of the Delta State University, Abraka, South-southern Nigeria. $10 \mathrm{~g}$ from 63 $\mu \mathrm{m}$ fractions of each sample were taken to the National Geochemical Laboratory of the Nigerian Geological Survey Agency in Kaduna, North-western Nigeria for X-Ray Fluorescence analysis

The stream sediment samples were crushed to less than 63 microns with the aid of a Tema vibrating mill before sieving to $60 \mu \mathrm{m}$. Beads for major element analysis expressed in oxide weight percent were prepared by first drying the pulverized samples in an oven at 110 degree Celsius for 24 hours to remove moisture content. 5 grams of the dry sample was weighed in the silica crucible and then ignited in the furnace at 1,000 degree Celsius for 2 to 3 hours for the calcination of impurities in the sample powder. Thereafter, samples were removed from furnace and allowed to cool to room temperature in desiccators. Each ignited sample powder was weighed again to determine the weight of calcinated impurities which were $\mathrm{H}_{2} \mathrm{O}^{-}, \mathrm{H}_{2} \mathrm{O}^{+}$and $\mathrm{CO}_{2} .1$ gram of stored ignited sample powder and exactly 5 times of flux (x-ray flux-type) 66\%:34\% (66\% lithium tetraborate: $34 \%$ lithium metaborate) was added to lower the vitrification temperature. The weighed mixture was properly mixed in a Platinum dish and ignited in the pre-set furnace (Eggon-2 Automatic Fuse Bead Maker) at 1,500 degree Celsius for 10 minutes to form glass bead. Each glass bead was labeled and slotted into the computerized XRF (Epsilon-5 Panalytical model) for major oxide analysis measured in weight percentages. Trace elemental analysis was carried out using compressed powder pellets. These pellets were prepared by weighing 3 grams of oven-dried samples and 3 grams flux (cellulose-powder) added as a binder and dispersive agent and shaken in small plastic containers for 12 minutes. The well mixed mixture was then compressed by applying pressure of $1,500 \mathrm{kgm}^{-2}$ using electronic compressor. The pellets were placed in the computer programmed XRF and the conditions for trace elemental analysis were set to give result in part per million (ppm).

\section{Results and Discussion}

\subsection{Results}

The summary of the descriptive statistics of the result of 
the XRF analysis is given in Table 1, while the cluster analysis dendrogram is displayed in Fig. 2.

\subsection{Discussion}

The results show concentrations of trace elements and major elements ( $\mathrm{Fe}$ and $\mathrm{Mn}$ ) in the River Gora sediments.

$\mathrm{Zr}$, Ba and $\mathrm{V}$ are considerately high in comparison to other trace elements in the samples. $\mathrm{Zr}$ ranges from 21-640 ppm with an average of $285 \mathrm{ppm}$ probably due to the complete weathering of the source bedrocks in the Minna area [6]. Ba has average concentration of $131.17 \mathrm{ppm}$. $\mathrm{V}$ has average concentration of $112.33 \mathrm{ppm}$. Sr has average concentration of $181.50 \mathrm{ppm}$.

$\mathrm{Cr}, \mathrm{Zn}, \mathrm{Rb}, \mathrm{Cu}, \mathrm{Sb}$ and $\mathrm{Ni}$ have the following concentrations: $\mathrm{Cr}$ (10-108 ppm), Zn (8-96 ppm), Rb (28-64 ppm), $\mathrm{Cu}$ (21-56 ppm), Sb (9-26 ppm) and Ni (3-10 ppm) and their mean concentrations are $43.87 \mathrm{ppm}, 39.58 \mathrm{ppm}$, $43.75 \mathrm{ppm}, 42.42 \mathrm{ppm}, 14.17 \mathrm{ppm}$ and $12.75 \mathrm{ppm}$, respectively.

$\mathrm{In}, \mathrm{Co}, \mathrm{Nb}, \mathrm{As}, \mathrm{Pb}$ and $\mathrm{Au}$ have moderately low concentrations in comparison to the other trace elements in the samples. The concentration of In range from 2-24 ppm with average values of $6.25 \mathrm{ppm}$, while $\mathrm{Co}$ and $\mathrm{Nb}$ have average concentrations of $10.92 \mathrm{ppm}$ and $11.41 \mathrm{ppm}$, respectively. On the other hand, $\mathrm{As}, \mathrm{Pb}$ and $\mathrm{Au}$ have average concentrations of $2.5 \mathrm{ppm}, 9.25 \mathrm{ppm}$ and $6.87 \mathrm{ppm}$, respectively (Table 1).

\subsubsection{Correlation Coefficient}

$\mathrm{Fe}$ has positive correlation with, $\mathrm{Ni}, \mathrm{Cr}$ and $\mathrm{Mn}$ but negatively correlated with $\mathrm{Au}, \mathrm{Rb}, \mathrm{Sb}, \mathrm{Pb}, \mathrm{Mo}$ and $\mathrm{Sr}$. On the other hand, $\mathrm{Mn}$ is positively correlated to $\mathrm{Rb}, \mathrm{Zn}, \mathrm{Sr}, \mathrm{Ni}$ and
$\mathrm{Pb}$ but negatively correlated to $\mathrm{Au}, \mathrm{Sb}, \mathrm{Ba}, \mathrm{As}, \mathrm{Pb}, \mathrm{Cu}, \mathrm{Mo}$ and $\mathrm{Cr}$. The result from the correlation analysis indicated that the oxides of $\mathrm{Fe}$ and $\mathrm{Mn}$ played principal role in the concentrations of the aforementioned elements, which were adsorbed by hydrated Fe- and $\mathrm{Mn}$ - oxyhydroxide grains dispersed in a secondary environment [7], or by the co-precipitation processes with $\mathrm{Fe}$ - and Mn-oxyhydroxides. However, the negative correlation of $\mathrm{Fe}$ and $\mathrm{Mn}$ with gold (Table 2) indicated the occurrence of gold in free native form and that in turn corroborated the field observations. The high concentrations of $\mathrm{Fe}, \mathrm{Cr}, \mathrm{V}, \mathrm{Ba}$ and $\mathrm{Sr}$ are indicative of probable felsic granitoids or schist source rocks in the study area.

Table 1. Summary of Descriptive Statistics of Results of Geochemical Analysis of Samples in ppm. $\mathrm{n}=24$

\begin{tabular}{|c|c|c|c|c|}
\hline Element & Min. & Max. & Mean & Std. Dev. \\
\hline $\mathrm{Au}$ & 2.30 & 11.00 & 6.88 & 2.39 \\
\hline $\mathrm{Rb}$ & 28.00 & 64.00 & 43.75 & 12.37 \\
\hline $\mathrm{Sb}$ & 9.00 & 26.00 & 14.17 & 4.59 \\
\hline $\mathrm{Ba}$ & 91.00 & 216.00 & 131.17 & 32.88 \\
\hline $\mathrm{Pb}$ & 2.00 & 48.00 & 9.25 & 13.47 \\
\hline $\mathrm{Zn}$ & 8.00 & 96.00 & 39.58 & 30.55 \\
\hline $\mathrm{Cu}$ & 21.00 & 56.00 & 42.42 & 10.74 \\
\hline $\mathrm{Mo}$ & 0.50 & 21.00 & 4.75 & 6.16 \\
\hline $\mathrm{Sr}$ & 12.00 & 319.00 & 181.5 & 86.60 \\
\hline $\mathrm{Ni}$ & 3.00 & 30.00 & 12.75 & 9.35 \\
\hline $\mathrm{Cr}$ & 10.00 & 108.00 & 43.87 & 32.12 \\
\hline $\mathrm{Fe}$ & 5.20 & 14.55 & 9.43 & 2.80 \\
\hline $\mathrm{Mn}$ & 0.05 & 0.31 & 0.19 & 0.08 \\
\hline
\end{tabular}

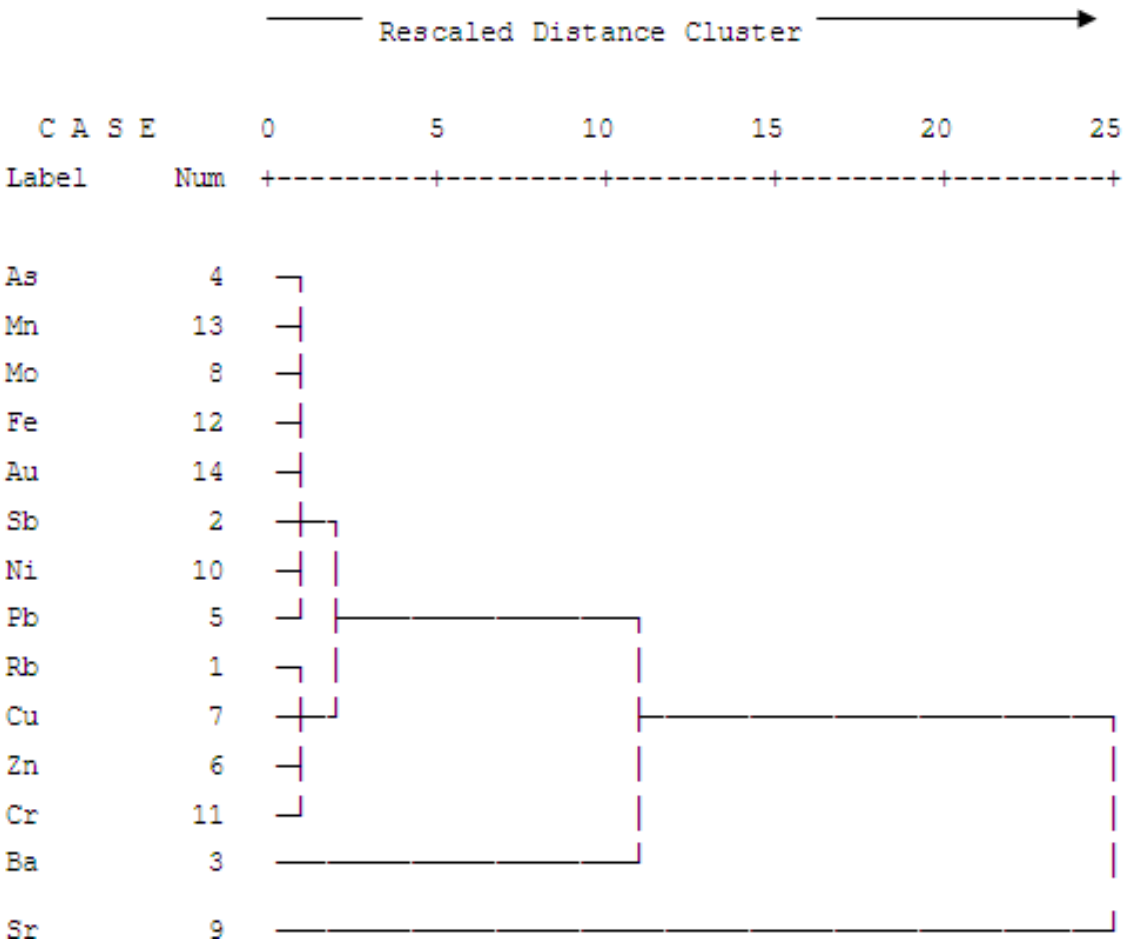

Figure 2. Cluster analysis dendrogram of trace elements in River Gora sediments using average linkage between groups 
Table 2. Pearson Correlation Coefficient Matrix of River Gora Sediment Samples

\begin{tabular}{|c|c|c|c|c|c|c|c|c|c|c|c|c|c|c|}
\hline & $\mathrm{Au}$ & $\mathrm{Rb}$ & $\mathrm{Sb}$ & $\mathrm{Ba}$ & $\mathrm{As}$ & $\mathrm{Pb}$ & $\mathrm{Zn}$ & $\mathrm{Cu}$ & $\mathrm{Mo}$ & $\mathrm{Sr}$ & $\mathrm{Ni}$ & $\mathrm{Cr}$ & $\mathrm{Fe}$ & $\mathrm{Mn}$ \\
\hline $\mathrm{Au}$ & 1.00 & & & & & & & & & & & & & \\
\hline $\mathrm{Rb}$ & 0.096 & 1.00 & & & & & & & & & & & & \\
\hline $\mathrm{Sb}$ & -0.584 & -0.311 & 1.00 & & & & & & & & & & & \\
\hline $\mathrm{Ba}$ & -0.005 & -0.200 & -0.416 & 1.00 & & & & & & & & & & \\
\hline $\mathrm{As}$ & -0.337 & -0.286 & 0.119 & 0.701 & 1.00 & & & & & & & & & \\
\hline $\mathrm{Pb}$ & 0.407 & -0.179 & -0.246 & 0.632 & 0.558 & 1.00 & & & & & & & & \\
\hline $\mathrm{Zn}$ & -0.664 & -0.650 & 0.602 & -0.068 & 0.353 & -0.262 & 1.00 & & & & & & & \\
\hline $\mathrm{Cu}$ & 0.048 & -0.458 & 0.205 & 0.365 & 0.207 & 0.443 & -0.560 & 1.00 & & & & & & \\
\hline $\mathrm{Mo}$ & 0.725 & 0.087 & -0.076 & -0.171 & -0.259 & 0.222 & -0.494 & 0.248 & 1.00 & & & & & \\
\hline $\mathrm{Sr}$ & -0.421 & 0.554 & 0.249 & -0.780 & -0.477 & -0.515 & -0.160 & -0.510 & 0.056 & 1.00 & & & & \\
\hline $\mathrm{Ni}$ & -0.046 & -0.716 & 0.368 & -0.152 & -0.179 & -0.444 & 0.677 & 0.236 & -0.321 & -0.270 & 1.00 & & & \\
\hline $\mathrm{Cr}$ & -0.163 & -0.583 & 0.078 & 0.263 & 0.202 & 0.245 & 0.429 & 0.529 & -0.365 & -0.434 & 0.461 & 1.00 & & \\
\hline $\mathrm{Fe}$ & -0.395 & -0.634 & -0.011 & 0.288 & 0.205 & -0.107 & 0.580 & 0.253 & -0.579 & -0.597 & 0.715 & 0.699 & 1.00 & \\
\hline $\mathrm{Mn}$ & -0.263 & 0.304 & -0.096 & -0.293 & -0.251 & -0.660 & 0.059 & -0.531 & -0.256 & 0.193 & 0.081 & -0.368 & 0.226 & 1.00 \\
\hline
\end{tabular}

Table 3. Stage and Clusters

\begin{tabular}{|c|c|c|c|c|c|c|}
\hline \multirow{2}{*}{ Stage } & \multicolumn{2}{|c|}{ Cluster } & \multirow{2}{*}{ Combined } & \multicolumn{2}{c|}{$\begin{array}{c}\text { Stage Cluster } \\
\text { First Appears }\end{array}$} & \multirow{2}{*}{$\begin{array}{c}\text { Next } \\
\text { Stage }\end{array}$} \\
\cline { 2 - 6 } & $\begin{array}{c}\text { Cluster } \\
1\end{array}$ & $\begin{array}{c}\text { Cluster } \\
\text { Coefficients }\end{array}$ & & $\begin{array}{c}\text { Cluster } \\
1\end{array}$ & $\begin{array}{c}\text { Cluster } \\
2\end{array}$ & \\
\hline 1 & 4 & 13 & 79.608 & 0 & 0 & 3 \\
\hline 2 & 12 & 14 & 285.359 & 0 & 0 & 4 \\
\hline 3 & 4 & 8 & 602.265 & 1 & 0 & 4 \\
\hline 4 & 4 & 12 & 664.442 & 3 & 2 & 6 \\
\hline 5 & 2 & 10 & 871.000 & 0 & 0 & 6 \\
\hline 6 & 2 & 4 & 1797.221 & 5 & 4 & 7 \\
\hline 7 & 2 & 5 & 2685.331 & 6 & 0 & 11 \\
\hline 8 & 1 & 7 & 4314.000 & 0 & 0 & 10 \\
\hline 9 & 6 & 11 & 12579.160 & 0 & 0 & 10 \\
\hline 10 & 1 & 6 & 14089.780 & 8 & 9 & 11 \\
\hline 11 & 1 & 2 & 21312.614 & 10 & 7 & 12 \\
\hline 12 & 1 & 3 & 167498.517 & 11 & 0 & 13 \\
\hline 13 & 1 & 9 & 390963.109 & 12 & 0 & 0 \\
\hline
\end{tabular}

\subsubsection{Multivariate Analysis}

The concentrations of the different groups of elements in the samples were subjected to multivariate statistical analysis using cluster analysis and principal component analysis to distinguish their various elemental associations.

\subsubsection{Cluster Analysis}

The result revealed two main clusters of variables (Table 3) classified into three groups, namely: cluster 1, cluster 2(a) and cluster 2(b). Cluster 1 is made up of $\mathrm{Ba}$ and $\mathrm{Sr}$, while cluster 2(a) consists of $\mathrm{Rb}, \mathrm{Cu}, \mathrm{Zn}, \mathrm{Cr}, \mathrm{Ba}$ and cluster 2(b) contains As, Mn, Mo, Fe, Au, Sb, Ni, Pb (Fig. 2).

Table 4. Kaiser-Meyer-Oklin (KMO) Measure of Sampling Adequacy (Communalities)

\begin{tabular}{|c|c|c|}
\hline Variable & Initial & Extraction \\
\hline $\mathrm{Au}$ & 1.000 & .886 \\
\hline $\mathrm{Rb}$ & 1.000 & .826 \\
\hline $\mathrm{Sb}$ & 1.000 & .929 \\
\hline $\mathrm{Ba}$ & 1.000 & .912 \\
\hline $\mathrm{As}$ & 1.000 & .907 \\
\hline $\mathrm{Pb}$ & 1.000 & .896 \\
\hline $\mathrm{Zn}$ & 1.000 & .859 \\
\hline $\mathrm{Cu}$ & 1.000 & .705 \\
\hline $\mathrm{Mo}$ & 1.000 & .774 \\
\hline $\mathrm{Sr}$ & 1.000 & .841 \\
\hline $\mathrm{Ni}$ & 1.000 & .925 \\
\hline $\mathrm{Cr}$ & 1.000 & .663 \\
\hline $\mathrm{Fe}$ & 1.000 & .969 \\
\hline $\mathrm{Mn}$ & 1.000 & .756 \\
\hline
\end{tabular}

\subsubsection{Principal Component Analysis (PCA)}

The data set of the trace elements and major elements (Fe and $\mathrm{Mn}$ ) were subjected to principal component analysis (PCA) involving three steps, namely: initial, extraction and rotation. Prior to the application of the principal component analysis, the appropriateness of the data for factor analysis was carried out. The use of the Kaiser-Meyer-Oklin (KMO) measure of sampling adequacy gave 0.705 to 0.969 (Table 4) that was interpreted to be very good to excellent because the 
recommended baseline value of 0.6 was exceeded. Moreover, the Bartlett's test of sphericity yielded statistical significance that further strengthened validity of the factorability of the correlation matrix of the heavy metal concentrations in the study area. Four component factors were extracted from the principal component analysis using eigenvalues greater than 1 and they explained $33.77 \%, 26.35 \%, 13.40 \%$ and $11.11 \%$ of the variance, respectively. The cumulative per cent of the variance of the initial eigenvalues and extracted sums of squared loading was $84.63 \%$ (Table 5). Furthermore, the scree plot revealed a clear break after the fourth component and that further verified the retention of the four components for further analysis and interpretation using Varimax with Kaiser Normalization and rotated solution. The four component solution revealed the cumulative per cent of the variance as $26.86 \%, 48.14 \%, 66.92 \%$ and $84.63 \%$ for components 1, 2, 3 and 4, respectively (Table 8). The Varimax with Kaiser Normalization and rotated solution gave cumulative per cent $(84.63 \%)$ of rotation sums of squared loading for component 4 (Table 8) which was consistent with the values revealed in the unrotated Principal Component Analysis extraction loading (Table 5). The unrotated and rotated solution principal component analysis matrices are given in Tables 6 and 7. Rotated principal component analysis solution (Table 7) gave the following elemental associations given as components, namely: component 1 ( $\mathrm{Sb}, \mathrm{Ba}, \mathrm{As}, \mathrm{Zn}, \mathrm{Cu}, \mathrm{Ni}, \mathrm{Cr}, \mathrm{Fe}$ ), component 2 (Ba, $\mathrm{As}, \mathrm{Pb}, \mathrm{Zn}, \mathrm{Cu}, \mathrm{Cr}, \mathrm{Fe}$ ), component 3 ( $\mathrm{Sb}, \mathrm{As}, \mathrm{Zn}, \mathrm{Sr}, \mathrm{Ni}$, $\mathrm{Cr}, \mathrm{Fe}$ ) and component 4 ( $\mathrm{Au}, \mathrm{Sb}, \mathrm{Ba}, \mathrm{As}, \mathrm{Pb}, \mathrm{Cu}, \mathrm{Mo}, \mathrm{Cr}$ ).

Table 5. Total Variance Explained: Initial Eigenvalues

\begin{tabular}{|c|c|c|c|c|c|c|}
\hline \multirow[b]{2}{*}{ Component } & \multicolumn{3}{|c|}{ Initial Eigenvalues } & \multicolumn{3}{|c|}{ Extraction Sums of Squared Loadings } \\
\hline & Total & $\%$ of Variance & Cumulative \% & Total & $\%$ of Variance & Cumulative \% \\
\hline 1 & 4.728 & 33.771 & 33.771 & 4.728 & 33.771 & 33.771 \\
\hline 2 & 3.689 & 26.349 & 60.120 & 3.689 & 26.349 & 60.120 \\
\hline 3 & 1.876 & 13.398 & 73.519 & 1.876 & 13.398 & 73.519 \\
\hline 4 & 1.555 & 11.110 & 84.628 & 1.555 & 11.110 & 84.628 \\
\hline 5 & .793 & 5.667 & 90.295 & & & \\
\hline 6 & .654 & 4.669 & 94.964 & & & \\
\hline 7 & .340 & 2.431 & 97.395 & & & \\
\hline 8 & .170 & 1.213 & 98.608 & & & \\
\hline 9 & .129 & .922 & 99.530 & & & \\
\hline 10 & .048 & .343 & 99.873 & & & \\
\hline 1 & .018 & .127 & 100.000 & & & \\
\hline 12 & .000 & .000 & 100.000 & & & \\
\hline 13 & .000 & .000 & 100.000 & & & \\
\hline 14 & .000 & .000 & 100.000 & & & \\
\hline
\end{tabular}

Table 6. Principal Component Analysis with UnRotated Solution

\begin{tabular}{|c|c|c|c|c|}
\hline \multirow{2}{*}{} & \multicolumn{4}{|c|}{ Component } \\
\cline { 2 - 5 } & 1 & 2 & 3 & 4 \\
\hline $\mathrm{Au}$ & -.493 & .606 & .306 & -.427 \\
\hline $\mathrm{Rb}$ & -.816 & -.059 & -.381 & .109 \\
\hline $\mathrm{Sb}$ & .299 & -.474 & .463 & .632 \\
\hline $\mathrm{Ba}$ & .437 & .685 & -.502 & .008 \\
\hline $\mathrm{As}$ & .507 & .386 & -.437 & .556 \\
\hline $\mathrm{Pb}$ & .165 & .903 & -.034 & .229 \\
\hline $\mathrm{Zn}$ & .733 & -.510 & .037 & .245 \\
\hline $\mathrm{Cu}$ & .486 & .497 & .471 & .013 \\
\hline $\mathrm{Mo}$ & -.491 & .436 & .583 & -.056 \\
\hline $\mathrm{Sr}$ & -.663 & -.537 & .175 & .287 \\
\hline $\mathrm{Ni}$ & .685 & -.486 & .334 & -.329 \\
\hline $\mathrm{Cr}$ & .765 & .136 & .169 & -.176 \\
\hline $\mathrm{Fe}$ & .839 & -.190 & -.187 & -.441 \\
\hline $\mathrm{Mn}$ & -.205 & -.619 & -.458 & -.347 \\
\hline
\end{tabular}

Table 7. Rotated Extraction Method using Varimax with Kaiser Normalization

\begin{tabular}{|c|c|c|c|c|}
\hline \multirow{2}{*}{} & \multicolumn{4}{|c|}{ Component } \\
\cline { 2 - 5 } & 1 & 2 & 3 & 4 \\
\hline $\mathrm{Au}$ & -.164 & -.128 & -.804 & .442 \\
\hline $\mathrm{Rb}$ & -.812 & -.088 & -.246 & -.314 \\
\hline $\mathrm{Sb}$ & .059 & -.282 & .880 & .267 \\
\hline $\mathrm{Ba}$ & .201 & .908 & -.215 & .044 \\
\hline $\mathrm{As}$ & .015 & .867 & .386 & .083 \\
\hline $\mathrm{Pb}$ & -.047 & .710 & -.229 & .580 \\
\hline $\mathrm{Zn}$ & .524 & .018 & .743 & -.175 \\
\hline $\mathrm{Cu}$ & .467 & .211 & -.012 & .665 \\
\hline $\mathrm{Mo}$ & -.279 & -.298 & -.413 & .661 \\
\hline $\mathrm{Sr}$ & -.621 & -.618 & .242 & -.120 \\
\hline $\mathrm{Ni}$ & .841 & -.334 & .304 & -.113 \\
\hline $\mathrm{Cr}$ & .752 & .228 & .117 & .179 \\
\hline $\mathrm{Fe}$ & .891 & .199 & .085 & -.357 \\
\hline $\mathrm{Mn}$ & -.053 & -.280 & -.064 & -.819 \\
\hline
\end{tabular}


Table 8. Total Variance Explained: Principal Component Analysis with Rotation Solution

\begin{tabular}{|c|c|c|c|c|c|c|}
\hline \multirow{2}{*}{ Component } & \multicolumn{3}{|c|}{ Extraction Sums of Squared Loadings } & \multicolumn{3}{c|}{ Rotation Sums of Squared Loadings } \\
\cline { 2 - 7 } & Total & \% of Variance & Cumulative \% & Total & \% of Variance & Cumulative \% \\
\hline 1 & 4.728 & 33.771 & 33.771 & 3.760 & 26.855 & 26.855 \\
\hline 2 & 3.689 & 26.349 & 60.120 & 2.980 & 21.285 & 48.140 \\
\hline 3 & 1.876 & 13.398 & 73.519 & 2.629 & 18.782 & 66.922 \\
\hline 4 & 1.555 & 11.110 & 84.628 & 2.479 & 17.706 & 84.628 \\
\hline
\end{tabular}

\section{Conclusions and Recommendations}

\subsection{Conclusion}

The negative correlation of $\mathrm{Fe}$ and $\mathrm{Mn}$ with gold indicated the occurrence of gold in free native form and that further corroborated with the field observation. The high concentrations of $\mathrm{Fe}, \mathrm{Cr}, \mathrm{V}, \mathrm{Ba}$ and $\mathrm{Sr}$ indicated probable felsic granitoids and schist source bedrocks in the study area. $\mathrm{As}, \mathrm{Mo}$ and $\mathrm{Sb}$, which are exceptional pathfinder elements for gold mineralization, were detected in the analyzed samples. The cluster analysis and principal component analysis revealed $\mathrm{Sb}, \mathrm{Ba}, \mathrm{As}, \mathrm{Pb}, \mathrm{Cu}, \mathrm{Mo}$ and $\mathrm{Cr}$ in elemental association with $\mathrm{Au}$. Therefore, in processing of the gold in the area, small-scale artisanal miners should be engage in best practice to avoid possible $\mathrm{Pb}$ and As poisoning.

\subsection{Recommendations}

The following recommendations are proffered:

That detailed geochemical and geophysical surveys should be carried out to establish reserve of gold in the study area.

That microchemical and electron microscopic studies should be carried on the gold grains, specks and nuggets to ascertain the best ore dressing techniques for the gold.

That small-scale artisanal miners should be advised to engage the best practice to avoid possible $\mathrm{Pb}$ and $\mathrm{As}$ poisoning.

\section{REFERENCES}

[1] N. P. Iloeje. A new geography of Nigeria, Academy Press Ltd., Lagos, 201, 1991.

[2] R. Black. Precambrian of the West Africa, Episodes 4, 3-8, 1980.

[3] K. C. Burke and J. F. Dewey. Orogeny in Africa, In: African Geology, T. F. J. Dessauvagie and A. J. Whiteman (eds.), Univ. Ibadan, 583-608, 1972.

[4] A. H Gandu, S. B Ojo, D. E. Ajakaye. A Gravity Study of the Precambrian in the Mal.ufashi Area of Kaduna State, Nigeria. Tectonophysics 126, 181-191, 1986.

[5] S. S. Dada. Crust Forming Ages and Proterozoic Crustal Evolution in Nigeria: Re-appraisal of Current Interpretations, Precambrian Research, 65-74, 2006.

[6] R. M. Key, C. C. Johnson, zircon concentrations in the fine fraction of stream sediments draining the Pan-African Dahomeyan Terrane in Nigeria. Appl. Geochem 27(8): 1525-1539, 2012.

[7] H. Holmstrom and B. Ohlander. Layers rich in Fe- and Mn-oxyhydroxides formed at the tailings-pond water interface, a possible trap for trace metals in flooded mine tailings, 74, 189-203, 2001. 